\title{
Numerical Optimization of the Process of Cellulose Isolation \\ by Peroxide Delignification of Birch Wood \\ in Acetic Acid-Water Medium \\ in the Presence of $\mathrm{TiO}_{2}$ Catalyst
}

\author{
Natalya V. Garyntseva*, Irina G. Sudakova, \\ Anna I. Chudina and Boris N. Kuznetsov \\ Institute of Chemistry and Chemical Technology SB RAS \\ FRC "Krasnoyarsk Science Center SB RAS" \\ Krasnoyarsk, Russian Federation
}

Received 10.01.2021, received in revised form 21.02.2021, accepted 10.03.2021

\begin{abstract}
The possibility of isolation of high-quality cellulose by peroxide delignification of birch wood in an acetic acid-water medium in the presence of a $\mathrm{TiO}_{2}$ catalyst at a temperature of $100{ }^{\circ} \mathrm{C}$ was shown. The influence of the process conditions (concentration of hydrogen peroxide and acetic acid, liquid/wood ratio (LWR)) on the yield and composition of cellulose products was established. Numerical optimization of the process was carried out using a full factorial experiment. The optimal conditions for isolation from birch wood a cellulose product with residual lignin content of $\leq 1 \mathrm{wt} . \%$ are: $\mathrm{CH}_{3} \mathrm{COOH}$ concentration 23.8 wt. $\%, \mathrm{H}_{2} \mathrm{O}_{2}$ concentration 4.9 wt.\%, LWR 14.9 , temperature $100{ }^{\circ} \mathrm{C}$, time $4 \mathrm{~h}$. Under these optimal conditions, the yield of a cellulose product with a cellulose content of 92.5 wt.\% was 49.9 wt.\%.
\end{abstract}

Keywords: birch wood, peroxide delignification, $\mathrm{TiO}_{2}$ catalyst, numerical optimization, cellulose product, composition.

Citation: Garyntseva N.V., Sudakova I.G., Chudina A.I., Kuznetsov B.N. Numerical optimization of the process of cellulose isolation by peroxide delignification of birch wood in acetic acid-water medium in the presence of $\mathrm{TiO}_{2}$ catalyst, J. Sib. Fed. Univ. Chem., 2021, 14(1), 120-132. DOI: 10.17516/1998-2836-0222

(C) Siberian Federal University. All rights reserved

This work is licensed under a Creative Commons Attribution-NonCommercial 4.0 International License (CC BY-NC 4.0).

* Corresponding author E-mail address: garyntseva@icct.ru 


\title{
Математическая оптимизация процесса \\ получения целлюлозы пероксидной \\ делигнификацией древесины березы \\ в среде уксусная кислота - вода \\ в присутствии катализатора $\mathrm{TiO}_{2}$
}

\author{
Н. В. Гарынцева, И. Г. Судакова, \\ А.И. Чудина, Б.Н. Кузнецов \\ Институт химии и химической технологии СО РАН \\ ФИЦ «Красноярский научный иุентр СО РАН» \\ Российская Федераџия, Красноярск
}

\begin{abstract}
Аннотация. Показана возможность получения качественного целлюлозного продукта путем пероксидной делигнификации древесины березы в среде уксусная кислота - вода в присутствии катализатора $\mathrm{TiO}_{2}$ при температуре $100^{\circ} \mathrm{C}$. Установлено влияние условий делигнификации (концентрации пероксида водорода и уксусной кислоты, гидромодуля) на выход и состав целлюлозных продуктов. Проведена математическая оптимизация процесса с применением полного факторного эксперимента. Найдены оптимальные условия получения из древесины березы целлюлозного продукта с содержанием остаточного лигнина $\leq 1$ мас.\%: концентрация $\mathrm{CH}_{3} \mathrm{COOH} 23,8$ мас.\%, концентрация $\mathrm{H}_{2} \mathrm{O}_{2} 4,9$ мас.\%, гидромодуль 14,9 , температура $100{ }^{\circ} \mathrm{C}$, продолжительность 4 ч. В оптимальных условиях процесса делигнификации выход целлюлозного продукта с содержанием целлюлозы 92,5 мас.\% составил 49,9 мас.\%.
\end{abstract}

Ключевые слова: древесина березы, пероксидная делигнификация, катализатор $\mathrm{TiO}_{2}$, математическая оптимизация, целлюлозный продукт, состав.

Цитирование: Гарынцева, Н.В. Математическая оптимизация процесса получения целлюлозы пероксидной делигнификацией древесины березы в среде уксусная кислота - вода в присутствии катализатора $\mathrm{TiO}_{2}$ / Н.В. Гарынцева, И.Г. Судакова, А.И. Чудина, Б.Н. Кузнецов // Журн. Сиб. федер. ун-та. Химия, 2021, 14(1). С. 120-132. DOI: 10.17516/19982836-0222

\section{Введение}

Береза является одной из наиболее распространенных пород деревьев на территории Российской Федерации. Ее запасы составляют около 10 млрд м ${ }^{3}$. Древесина березы - это ценное сырье для производства такого композиционного материала, как фанера [1]. При этом на деревоперерабатывающих предприятиях образуется большое количество отходов (более $50 \%$ от исходной древесины) в виде опилок и стружки, которые необходимо утилизировать [2].

Вместе с тем древесина березы представляет особый интерес для химической переработки не только в целлюлозу, но и в другие химические продукты, пользующиеся высоким спросом: фурфурол, ксилоза, ксилит, ванилин и сиреневый альдегид [3-5]. 
Традиционные сульфатные и сульфитные способы получения целлюлозы достаточно энергозатратны, а также наносят значительный ущерб окружающей среде за счет использования вредных серо- и хлорсодержащих делигнифицирующих агентов [6].

Альтернативными способами получения целлюлозы являются органосольвентные методы делигнификации, в основе которых лежит использование органических сред (спиртов, карбоновых кислот, кетонов) [7-9]. Данные методы в отличие от традиционных позволяют использовать разное по природе растительное сырье (в том числе отходы лесопиления), осуществлять комплексную переработку древесной биомассы с утилизацией гемицеллюлоз и лигнина, а также регенерировать и возвращать в технологический цикл растворители путем их отгонки при небольших энергетических затратах.

Одним из перспективных способов получения целлюлозы выступает делигнификация лигноцеллюлозного сырья в среде органических кислот (уксусной и муравьиной) в присутствии экологически безопасного окислителя пероксида водорода [10-12].

В процессе «Milox» делигнификация осуществляется с использованием 80-90\%-х растворов кислот (уксусной или муравьиной) при температура $80-120^{\circ} \mathrm{C}$ в течение $2-5$ ч, в две или три стадии $[13,14]$.

Ранее нами была показана возможность получения качественной целлюлозы путем одностадийной пероксидной делигнификации древесины осины в нормальных условиях (атмосферное давление, температура $\leq 100^{\circ} \mathrm{C}$ ) в среде уксусная кислота - вода в присутствии сернокислотного катализатора [15].

Актуальная задача - разработка новых экологически безопасных и экономически эффективных оптимизированных процессов получения целлюлозы из древесного сырья.

В данной работе установлено влияние параметров процесса пероксидной делигнификации древесины березы в среде уксусной кислоты в присутствии катализатора $\mathrm{TiO}_{2}$ на выход и состав целлюлозных продуктов и проведена математическая оптимизация процесса с целью подбора условий для получения качественного целлюлозного продукта с низким содержанием остаточного лигнина.

\section{Экспериментальная часть}

В качестве исходного сырья использовали древесные опилки (фракция 2,5-5 мм) березы повислой (Betula Pendula), произрастающей в Красноярском крае. Определение химического состава древесных опилок проводили по стандартным, описанным ранее методикам [16]. Содержание основных компонентов древесины березы (мас.\%): целлюлоза - 46,8; лигнин - 21,7; гемицеллюлозы - 27,3; экстрактивные вещества $-3,5$; зола - 0,34.

Делигнификацию измельченной древесины березы осуществляли в стеклянном реактоpe, снабженном механической мешалкой и обратным холодильником. Раствор для делигнификации готовили из смеси ледяной уксусной кислоты, содержание которой варьировали от 15 до 35 мас.\%, пероксида водорода от 3 до 6 мас.\%. Значение величины гидромодуля составляло 5,10 и 15. В качестве катализатора использовали промышленный $\mathrm{TiO}_{2}$ (DuPont, USA) в количестве $1 \%$ от массы древесины. Процесс осуществляли в течение 4 ч при постоянном перемешивании и температуре $100{ }^{\circ} \mathrm{C}$. 
После делигнификации твердый остаток отделяли от щелока фильтрованием на воронке Бюхнера, промывали до нейтральной реакции промывных вод, высушивали до воздушносухого состояния и анализировали. Определение содержания целлюлозы, лигнина и легкогидролизуемых полисахаридов проводили по общепринятым методикам [16].

\section{Результаты и обсуждение}

Выход и состав целлюлозных продуктов, получаемых в исследуемом процессе пероксидной делигнификации древесины березы, зависит от следующих параметров: температура, продолжительность, концентрация реагентов (уксусной кислоты и пероксида водорода), соотношение раствор/твердая фаза (гидромодуль).

Цель настоящего исследования состояла в поиске более мягких, чем промышленные, условий делигнификации: температура процесса $\leq 100{ }^{\circ} \mathrm{C}$, невысокая концентрация реагентов с одновременным обеспечением высокого выхода целлюлозного продукта и низким содержанием в нем остаточного лигнина.

Ранее проведенное исследование кинетики пероксидной делигнификации древесины березы в интервале температур $70-100{ }^{\circ} \mathrm{C}$ показало, что для получения целлюлозного продукта с низким содержанием остаточного лигнина необходимо проводить процесс при температуре $100{ }^{\circ} \mathrm{C}$ в течение 4 ч [15].

Данные по влиянию других параметров: концентрации пероксида водорода и уксусной кислоты, а также гидромодуля (ГМ) процесса на выход и состав целлюлозных продуктов представлены на рис. $1 A-B$.

Начальная концентрация пероксида водорода оказывает значительное влияние на выход и содержание основных компонентов в получаемых целлюлозных продуктах (рис. $1 A$ ). Увеличение концентрации пероксида водорода с 3 до 6 мас.\% приводит к значительному уменьшению содержания остаточного лигнина с 7,8 до 0,7 мас.\% и увеличению содержания целлюлозы с 82,1 до 91,2 мас.\%. При этом выход целлюлозного продукта снижается на 10 \% с 67,5 до 56,5 мас.\%. Содержание гемицеллюлоз в целлюлозных продуктах уменьшается, но незначительно - с 9,8 до 6,7 мас.\%

Согласно полученным данным (рис. 1Б), глубокая делигнификация древесины березы может осуществляться при достаточно низких значениях концентрации уксусной кислоты: 2535 мас.\%, полученный целлюлозный продукт содержит 1,5 и 0,5 мас.\% остаточного лигнина и 8,8 и 6,9 мас.\% гемицеллюлоз соответственно, сохраняя при этом высокий выход - около 50 мас.\%.

Гидромодуль - это важный параметр, позволяющий регулировать процессы диффузии в гетерогенных средах. При оптимизации процесса необходимо найти разумный компромисс, обеспечивающий, с одной стороны, невысокий расход реагентов (невысокий ГМ), с другой возможность снятия внешних диффузионных ограничений (высокий ГМ). В ходе исследования установлено, что при гидромодулях 10 и 15 образуется целлюлозный продукт с низким содержанием остаточного лигнина (3,7 \% и 0,8 мас.\% соответственно), рис. $1 B$. Уменьшение величины гидромодуля до 5 увеличивает выход целлюлозного продукта до 70,2 мас.\%, но снижает его качество. Высокое содержание лигнина в целлюлозном продукте (9,2 мас.\%) является следствием затруднения диффузии окисляющего реагента в межклеточное пространство и отвода продуктов окисления лигнина в раствор.

$$
-123-
$$


A

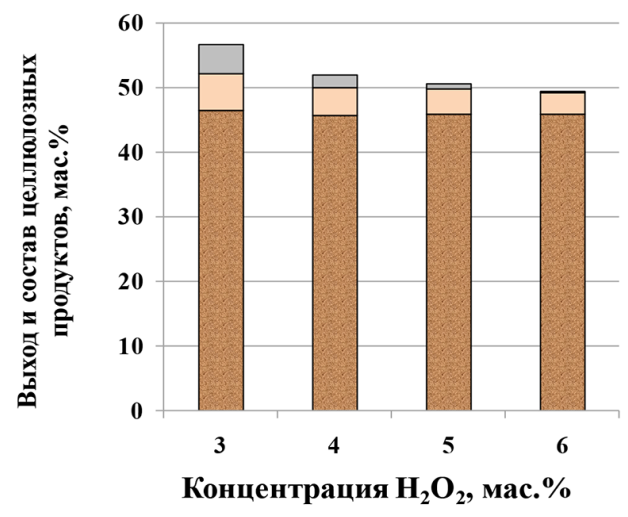

Б



B

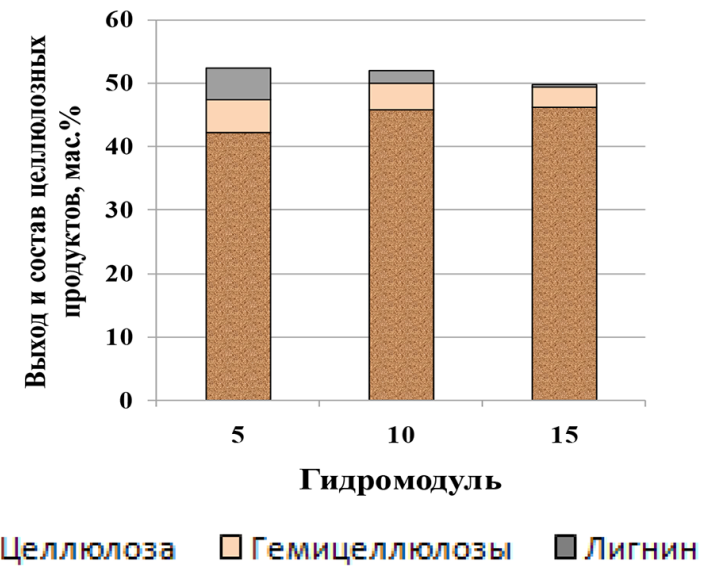

Рис. 1. Влияние концентрации пероксида водорода (А), уксусной кислоты (Б) и гидромодуля процесса (В) на выход и состав целлюлозных продуктов, полученных пероксидной делигнификацией древесины березы: А - $\mathrm{CH}_{3} \mathrm{COOH} 25$ мас.\%, ГМ 10; Б - $\mathrm{H}_{2} \mathrm{O}_{2} 5$ мас.\%, ГМ 10; В - $\mathrm{CH}_{3} \mathrm{COOH} 25$ мас.\%, $\mathrm{H}_{2} \mathrm{O}_{2} 5$ мас.\%. Температура $100{ }^{\circ} \mathrm{C}$, продолжительность 4 ч, катализатор $\mathrm{TiO}_{2}$

Fig. 1. Influence of hydrogen peroxide concentration (A), acetic acid concentration (Б) and LWR (B) on yield and composition of cellulose products obtained by hydrogen peroxide delignification of birch wood: $\mathrm{A}-\mathrm{CH}_{3} \mathrm{COOH}$ 25 wt.\%, LWR10; $\mathrm{B}-\mathrm{H}_{2} \mathrm{O}_{2} 5$ wt.\%, LWR10; $\mathrm{B}-\mathrm{CH}_{3} \mathrm{COOH} 25$ wt.\%, $\mathrm{H}_{2} \mathrm{O}_{2} 5$ wt.\%. Temperature $100{ }^{\circ} \mathrm{C}$, time 4 h, catalyst $\mathrm{TiO}_{2}$

Из полученных экспериментальных данных следует, что концентрации реагирующих веществ и гидромодуль процесса оказывают значительное влияние на выход и состав целлюлозных продуктов.

Поэтому при оптимизации процесса делигнификации древесины березы в качестве переменных факторов использованы: $\mathrm{X}_{1}$ - концентрация пероксида водорода в раствоpe (3-6 мас.\%), $\mathrm{X}_{2}$ - гидромодуль процесса (5-15), $\mathrm{X}_{3}$ - концентрация уксусной кислоты в растворе (15-35 мас.\%). В качестве выходных параметров оптимизации выбраны: $Y_{1}-$ выход целлюлозного продукта, \%; $Y_{2}$ - содержание целлюлозы в целлюлозном продукте, $\% ; Y_{3}$ - содержание остаточного лигнина; $Y_{4}-$ содержание остаточных гемицеллюлоз в целлюлозном продукте. Постоянные параметры: температура $100{ }^{\circ} \mathrm{C}$, продолжительность 4 ч. 
Математическую оптимизацию проводили с применением полного факторного эксперимента (ПФЭ) типа $2^{3}$. ПФЭ позволяет получить уравнение регрессии первого порядка и оценить линейные и парные взаимодействия параметров процесса. Общий вид уравнения регрессии для ПФЭ $2^{3}$ следующий:

$$
\mathrm{Y}=\mathrm{b}_{0}+\mathrm{b}_{1} \mathrm{X}_{1}+\mathrm{b}_{2} \mathrm{X}_{2}+\mathrm{b}_{3} \mathrm{X}_{3}+\mathrm{b}_{12} \mathrm{X}_{1} \mathrm{X}_{2}+\mathrm{b}_{23} \mathrm{X}_{2} \mathrm{X}_{3}+\mathrm{b}_{13} \mathrm{X}_{1} \mathrm{X}_{3}
$$

В матрице планирования эксперимента (табл. 1) независимые переменные показаны в натуральных и кодированных единицах. Выходные параметры, отображенные в таблице, представляют собой среднее значение трех экспериментов.

Таблица 1. Матрица оптимизации процесса пероксидной делигнификации древесины березы и результаты ее реализации

Table 1. Matrix of optimization of the process of birch wood peroxide delignification and the results of its implementation

\begin{tabular}{|c|c|c|c|c|c|c|c|c|c|c|c|c|c|}
\hline \multirow[b]{2}{*}{ № } & \multicolumn{3}{|c|}{ Натуральные переменные } & \multicolumn{3}{|c|}{$\begin{array}{c}\text { Кодированные } \\
\text { переменные }\end{array}$} & \multicolumn{3}{|c|}{ Взаимодействия } & \multicolumn{4}{|c|}{ Выходные параметры } \\
\hline & $\begin{array}{c}X_{1} \\
\mathrm{H}_{2} \mathrm{O}_{2} \\
(\%)\end{array}$ & $\begin{array}{c}X_{2} \\
\Gamma \mathrm{M}\end{array}$ & $\begin{array}{c}X_{3} \\
\mathrm{CH}_{3} \mathrm{COOH} \\
(\%)\end{array}$ & $X_{1}$ & $X_{2}$ & $X_{3}$ & $X_{12}$ & $X_{13}$ & $X_{23}$ & 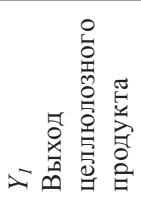 &  & 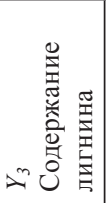 & 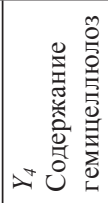 \\
\hline 1 & 3 & 5 & 15 & -1 & -1 & -1 & +1 & +1 & +1 & 70,4 & 66,3 & 18,2 & 15,2 \\
\hline 2 & 3 & 5 & 35 & -1 & -1 & +1 & +1 & -1 & -1 & 64,2 & 72,4 & 14,5 & 12,8 \\
\hline 3 & 3 & 15 & 15 & -1 & +1 & -1 & -1 & +1 & -1 & 59,2 & 78,5 & 8,2 & 13 \\
\hline 4 & 3 & 15 & 35 & -1 & +1 & +1 & -1 & -1 & +1 & 54,1 & 86,2 & 4,3 & 9,2 \\
\hline 5 & 6 & 5 & 15 & +1 & -1 & -1 & -1 & -1 & +1 & 59,4 & 78,4 & 9,8 & 11,5 \\
\hline 6 & 6 & 5 & 35 & +1 & -1 & +1 & -1 & +1 & -1 & 55,1 & 84 & 7,5 & 8,2 \\
\hline 7 & 6 & 15 & 15 & +1 & +1 & -1 & +1 & -1 & -1 & 53 & 87,9 & 2,5 & 9,3 \\
\hline 8 & 6 & 15 & 35 & +1 & +1 & +1 & +1 & +1 & +1 & 50,7 & 92,5 & 0,5 & 6,7 \\
\hline
\end{tabular}

Регрессионный анализ данных был проведен с использованием программы Excell. Вклад каждого фактора в результат процесса определяли по значению критерия эффективности (F-Ratio) и уровню значимости ( $P$-Value) - он тем существеннее, чем больше величина критерия эффективности (дисперсионного отношения Фишера F-Ratio) и чем меньше уровень значимости (P-Value).

Дисперсионный анализ показал, что влияние всех факторов $\mathrm{X}_{1}, \mathrm{X}_{2}$ и $\mathrm{X}_{3}$ на выходные параметры $\mathrm{Y}_{1}, \mathrm{Y}_{2}, \mathrm{Y}_{3}, \mathrm{Y}_{4}$ статистически значимо, их уровень значимости меньше 0,05 (табл. 2). Эффективность считают приемлемой при $\mathrm{F} \geq 5 . .8$ [17].

Уравнения регрессии в кодированных переменных следующие:

$$
\begin{gathered}
Y_{1}=58,2625-4,0125 \cdot X_{2}-3,7125 \cdot X_{1}-2,2375 \cdot X_{3}+1,3125 \cdot X_{1} X_{2}+0,5875 \cdot X_{1} X_{3} \\
Y_{2}=80,775+5,5 \cdot X_{2}+4,925 \cdot X_{1}+3,0 \cdot X_{3}-1 \cdot X_{1} X_{2}, \\
-125-
\end{gathered}
$$




$$
\begin{aligned}
& Y_{3}=8,1875-4,3125 \cdot X_{2}-3,1125 \cdot X_{1}-1,4875 \cdot X_{3}+0,7375 \cdot X_{1} X_{2}+0,4125 \cdot X_{1} X_{3}, \\
& Y_{4}=10,7375-1,8175 \cdot X_{1}-1,1875 \cdot X_{2}-1,5125 \cdot X_{3} .
\end{aligned}
$$

Уравнения регрессии, полученные именно в кодированных переменных, позволяют проводить интерпретацию полученной модели. Только в этом случае на коэффициенты не влияет масштаб факторов и по величине и знаку коэффициентов можно судить о степени влияния того или иного фактора на выходной параметр.

По уравнениям (2-4) видно, что на выходные параметры $\mathrm{Y}_{1}, \mathrm{Y}_{2}$ и $\mathrm{Y}_{3}$ наибольшее влияние оказывает гидромодуль процесса $\left(\mathrm{X}_{2}\right)$ и концентрация пероксида водорода $\left(\mathrm{X}_{1}\right)$. В меньшей степени сказывается влияние концентрации уксусной кислоты. Так как коэффициенты в уравнениях (2) и (4) при $\mathrm{X}_{1}, \mathrm{X}_{2}$ и $\mathrm{X}_{3}$ отрицательные, то с увеличением этих факторов уменьшается отклик, т. е. уменьшается выход целлюлозного продукта и содержание в нем остаточного лигнина. В уравнении (3), наоборот, положительные коэффициенты при $\mathrm{X}_{1}, \mathrm{X}_{2}$ и $\mathrm{X}_{3}$ свидетельствуют об увеличении содержания целлюлозы в целлюлозном продукте при увеличении гидромодуля и концентрации пероксида водорода и уксусной кислоты. Парные взаимодействия $\mathrm{X}_{2} \mathrm{X}_{3}$ для $\mathrm{Y}_{1}, \mathrm{X}_{1} \mathrm{X}_{3}$ и $\mathrm{X}_{2} \mathrm{X}_{3}$ для $\mathrm{Y}_{2}, \mathrm{X}_{2} \mathrm{X}_{3}$ для $\mathrm{Y}_{3}$ оказались статистически незначимы, поэтому не были включены в уравнения регрессии.

В уравнении регрессии (5), полученном для выходного параметра $\mathrm{Y}_{4}$, коэффициенты при $\mathrm{X}_{1}, \mathrm{X}_{2}$ и $\mathrm{X}_{3}$ имеют практически одинаковые и невысокие значения $(1,5-1,9)$. Это свидетельствует о незначительном влиянии изменения гидромодуля и концентрации реагирующих веществ на содержание остаточных гемицеллюлоз в целлюлозном продукте. Это полностью согласуется с полученными ранее экспериментальными данными (рис. 1). Отрицательные значения коэффициентов указывают на уменьшение содержания гемицеллюлоз при увеличении переменных факторов процесса.

На хорошие прогностические свойства полученных математических моделей указывают высокие значения коэффициентов детерминации регрессионных уравнений $(0,97-0,99)$. На-

Таблица 2. Результаты дисперсионного анализа выходных параметров $\mathrm{Y}_{1}, \mathrm{Y}_{2}, \mathrm{Y}_{3}$ и $\mathrm{Y}_{4}$

\begin{tabular}{|c|c|c|c|c|c|c|c|c|}
\hline \multirow[b]{2}{*}{$\begin{array}{l}\text { Источник } \\
\text { дисперсии }\end{array}$} & \multicolumn{2}{|c|}{$Y_{1}$} & \multicolumn{2}{|c|}{$Y_{2}$} & \multicolumn{2}{|c|}{$Y_{3}$} & \multicolumn{2}{|c|}{$Y_{4}$} \\
\hline &  &  & 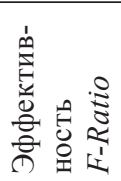 & 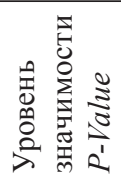 & 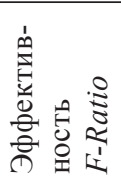 &  & 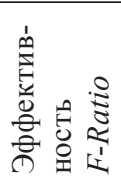 &  \\
\hline $\mathrm{X}_{1}$ & 33 & 0,0192 & 15 & 0,0419 & 49 & 0,0127 & 7 & 0,0915 \\
\hline $\mathrm{X}_{2}$ & 35 & 0,0178 & 16 & 0,0375 & 69 & 0,0092 & 6 & 0,1384 \\
\hline $\mathrm{X}_{3}$ & 19 & 0,0319 & 9 & 0,0686 & 23 & 0,0267 & 6 & 0,1093 \\
\hline $\mathrm{X}_{1} \mathrm{X}_{2}$ & 11 & 0,0544 & 5 & 0,0900 & 11 & 0,0538 & 1 & 0,4999 \\
\hline $\mathrm{X}_{1} \mathrm{X}_{3}$ & 5 & 0,1204 & 1 & 0,3981 & 6 & 0,0957 & 0,1 & 0,9096 \\
\hline $\mathrm{X}_{2} \mathrm{X}_{3}$ & 3 & 0,1798 & 0,2 & 0,8556 & 0,2 & 0,8743 & 0,3 & 0,7951 \\
\hline $\mathrm{R}^{2}$ & \multicolumn{2}{|c|}{0,99} & \multicolumn{2}{|c|}{0,98} & \multicolumn{2}{|c|}{0,99} & \multicolumn{2}{|c|}{0,97} \\
\hline
\end{tabular}

Table 2. Results of dispersion analysis of output parameters $\mathrm{Y}_{1}, \mathrm{Y}_{2}, \mathrm{Y}_{3}$ and $\mathrm{Y}_{4}$ 
A

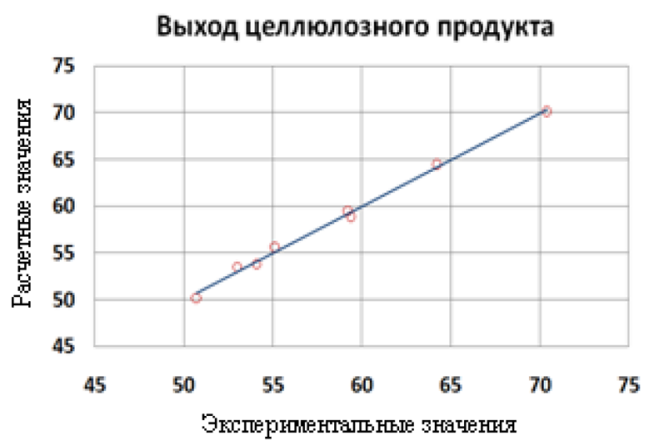

B

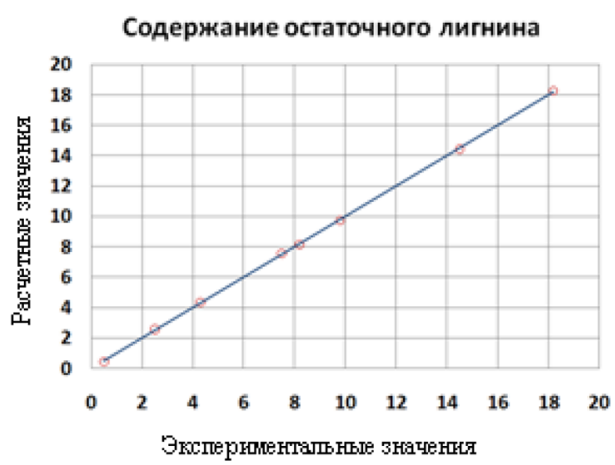

Б



$\Gamma$



Рис. 2. Сравнение экспериментальных и расчетных значений выхода целлюлозного продукта (А), содержание целлюлозы в целлюлозном продукте (Б), содержание остаточного лигнина в целлюлозном продукте (В), содержание остаточных гемицеллюлоз в целлюлозном продукте (Г) в процессе пероксидной делигнификации древесины березы

Fig. 2. Comparison of experimental and calculated values of the cellulose product yield (A), cellulose content in a cellulose product (Б), residual lignin content in a cellulose product (B), content of residual hemicelluloses in a cellulose product $(\Gamma)$ in the process of peroxide delignification of birch wood

глядно это представлено на рис. 2, где приведены графики сравнения значений выходных параметров $\mathrm{Y}_{1}, \mathrm{Y}_{2}, \mathrm{Y}_{3}$ и $\mathrm{Y}_{4}$, полученных в эксперименте, со значениями, прогнозируемыми по моделям. Прямые линии соответствуют расчетным (прогнозируемым) значениям $\mathrm{Y}_{1}, \mathrm{Y}_{2}, \mathrm{Y}_{3}$ и $\mathrm{Y}_{4}$, точки - экспериментальным данным.

Уравнения регрессии в натуральных переменных следующие:

$$
\begin{aligned}
& Y_{1}=97,2375-5,2041 \cdot X_{1}-1,7837 \cdot X_{2}-0,4775 \cdot X_{3}+0,175 \cdot X_{1} X_{2}+0,039 \cdot X_{1} X_{3}, \\
& Y_{2}=38,50+5,3666 \cdot X_{1}+1,6625 \cdot X_{2}-0,442 \cdot X_{3}-0,1333 \cdot X_{1} X_{2}, \\
& Y_{3}=37,45-3,7458 \cdot X_{1}-1,3112 \cdot X_{2}-0,275 \cdot X_{3}+0,0983 \cdot X_{1} X_{2}+0,0275 \cdot X_{1} X_{3}, \\
& Y_{4}=23,75-1,6208 \cdot X_{1}-0,3512 \cdot X_{2}-0,145 \cdot X_{3} .
\end{aligned}
$$

С помощью данных уравнений можно рассчитать значения исследуемых величин (выход целлюлозного продукта, содержание целлюлозы, остаточного лигнина и гемицеллюлоз в цел- 
люлозном продукте), придавая факторам значения, которые должны лежать между нижним и верхним уровнями.

На рис. 3 представлены поверхности отклика, демонстрирующие влияние наиболее значимых переменных факторов процесса (концентрации пероксида водорода и гидромодуля) на выходные параметры.

Согласно полученным данным (рис. $3 A$ ), факторные координаты точки, в которой выход целлюлозного продукта достигает максимальной величины 70,4 мас.\% (без ограничений по другим выходным параметрам): концентрация $\mathrm{H}_{2} \mathrm{O}_{2} 3 \%$, гидромодуль 5. Однако без учета ограничения на степень делигнификации эта информация ценности не несет. Приемлемая величина выхода целлюлозного продукта находится в пределах 53-49 мас.\% и соответствует условиям процесса: 5-6 мас.\% $\mathrm{H}_{2} \mathrm{O}_{2}$ и гидромодуль 15-16. Максималь-

A

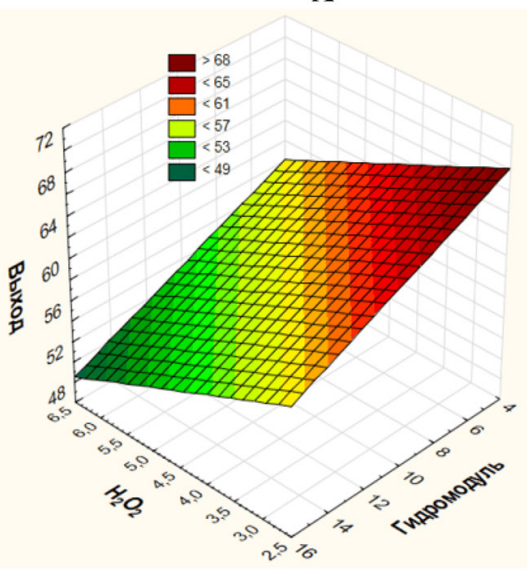

B

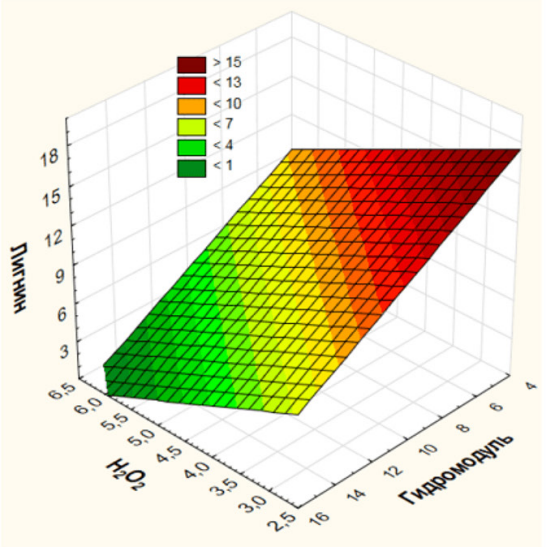

Б

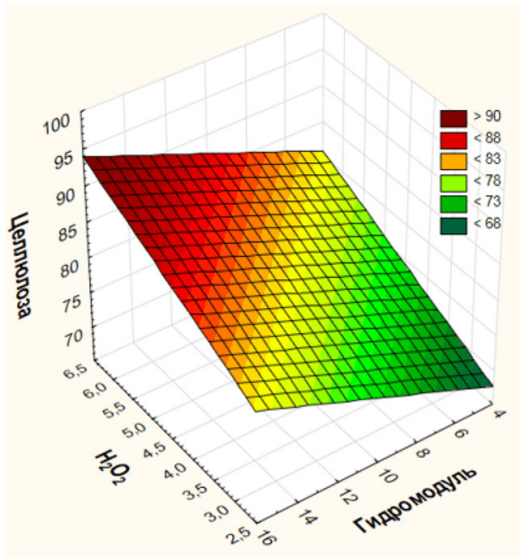

$\Gamma$

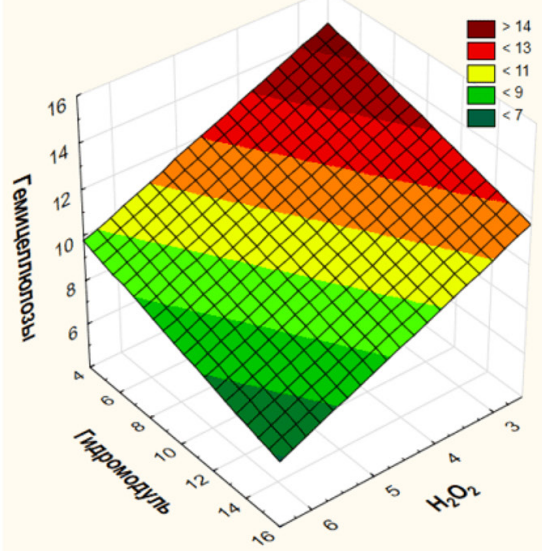

Рис. 3. Поверхности отклика выходных параметров $Y_{1}$ (выхода целлюлозного продукта (А), $Y_{2}$ (содержания целлюлозы (Б), $\mathrm{Y}_{3}$ (лигнина (В) и $\mathrm{Y}_{4}$ (гемицеллюлоз (Г) в целлюлозном продукте)) от концентрации пероксида водорода $\left(\mathrm{X}_{1}\right.$, мас.\%) и гидромодуля $\left(\mathrm{X}_{2}\right)$ процесса делигнификации древесины березы в присутствии катализатора $\mathrm{TiO}_{2}$

Fig. 3. Response surfaces of output parameters $Y_{1}$ (yield of cellulose product (A), $Y_{2}$ (content of cellulose (Б), $\mathrm{Y}_{3}$ (lignin (B) and $\mathrm{Y}_{4}$ (hemicelluloses $(\Gamma)$ in a cellulose product)) on the concentration of hydrogen peroxide $\left(\mathrm{X}_{1}\right.$, wt.\%) and LWR $\left(\mathrm{X}_{2}\right)$ of birch wood delignification process in the presence of $\mathrm{TiO}_{2}$ catalyst 
ное значение содержания целлюлозы в целлюлозном продукте - 92,5 мас.\% - достигается при следующих значениях переменных факторов: концентрация пероксида водорода: 5,5-6 мас.\%, гидромодуль 14-16 (рис. 3Б). Содержание остаточного лигнина в целлюлозном продукте менее 1 мас.\% достигается в интервале варьирования переменных факторов процесса: $\mathrm{H}_{2} \mathrm{O}_{2}$ 5-6 мас.\%, гидромодуль 15-16 (рис. 3B). Минимальному содержанию гемицеллюлоз в целлюлозном продукте (< 7 мас.\%) соответствуют условия: $\mathrm{H}_{2} \mathrm{O}_{2} 4,7-5,7$ мас.\%, гидромодуль 8-13 (рис. $3 \Gamma$ ).

Рисунки 4, 5 и 6 отображают зависимость $\mathrm{Y}_{2}, \mathrm{Y}_{3}$ и $\mathrm{Y}_{4}$ от выхода целлюлозного продукта $\mathrm{Y}_{1}$. Видно, что между содержанием остаточного лигнина, содержанием остаточных гемицеллюлоз и выходом целлюлозного продукта существует прямая зависимость. Целлюлозный продукт, полученный с высоким выходом, будет содержать значительное количество остаточного лигнина и гемицеллюлоз. Максимальное содержание целлюлозы наблюдается при минимальном значении выхода целлюлозного продукта.

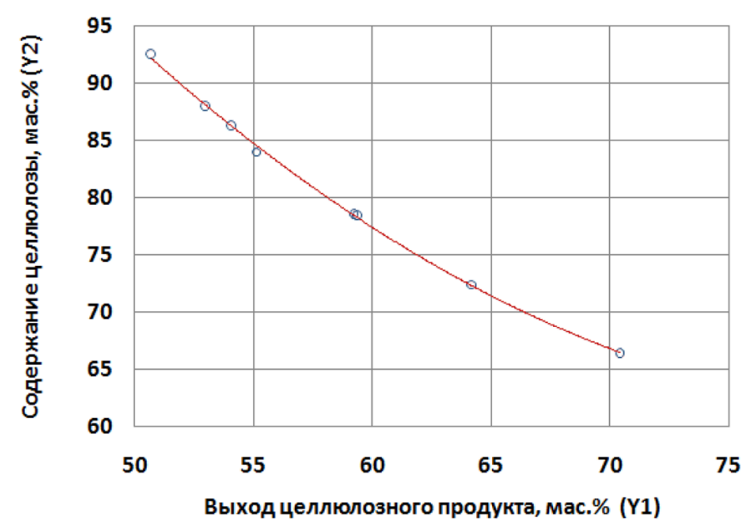

Рис. 4. Зависимость $\mathrm{Y}_{2}$ (содержание целлюлозы в целлюлозном продукте) от $\mathrm{Y}_{1}$ (выход целлюлозного продукта)

Fig. 4. Dependence of $Y_{2}$ (cellulose content in cellulose product) on $Y_{1}$ (yield of cellulose product)

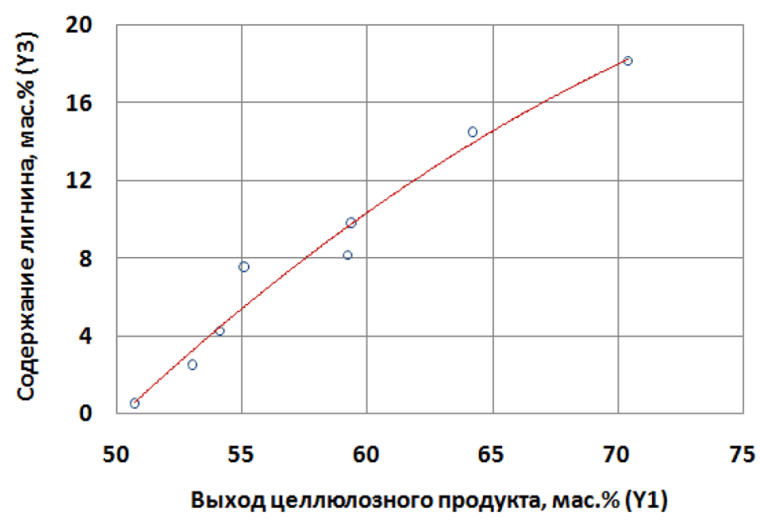

Рис. 5. Зависимость $\mathrm{Y}_{3}$ (содержание остаточного лигнина) от $\mathrm{Y}_{1}$ (выход целлюлозного продукта)

Fig. 5. Dependence of $\mathrm{Y}_{3}$ (residual lignin content) on $\mathrm{Y}_{1}$ (cellulose product yield)

$$
-129-
$$




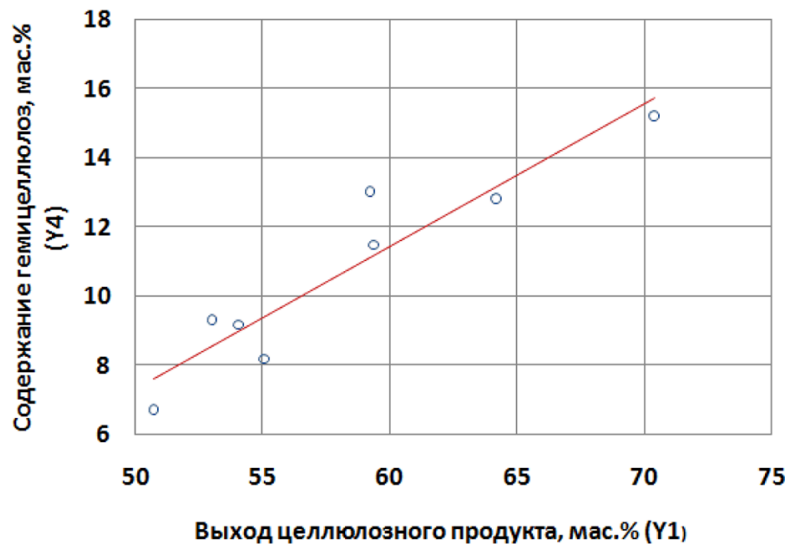

Рис. 6. Зависимость $\mathrm{Y}_{4}$ (содержание остаточных гемицеллюлоз) от $\mathrm{Y}_{1}$ (выход целлюлозного продукта)

Fig. 6. Dependence of $\mathrm{Y}_{4}$ (content of residual hemicelluloses) on $\mathrm{Y}_{1}$ (yield of cellulose product)

Таблица 3. Характеристики целлюлозы, полученной из древесины березы в оптимальных условиях процесса пероксидной делигнификации

Table 3. Characteristics of cellulose obtained from birch wood under optimal conditions of the peroxide delignification process

\begin{tabular}{|c|c|c|c|c|c|c|}
\hline \multirow[b]{2}{*}{ Образец } & \multirow{2}{*}{$\begin{array}{c}\text { Выход, } \\
\text { мас.\% }\end{array}$} & \multicolumn{3}{|c|}{ Химический состав, мас .\% } & \multirow[b]{2}{*}{$\mathrm{C} \Pi$} & \multirow[b]{2}{*}{ ИК } \\
\hline & & целлюлоза & лигнин & $\begin{array}{c}\text { гемицел- } \\
\text { люлозы }\end{array}$ & & \\
\hline Целлюлоза из древесины березы & 49,9 & 92,5 & 0,5 & 6,7 & 456 & 0,78 \\
\hline
\end{tabular}

Наличие взаимосвязи между всеми выходными параметрами позволяет использовать наглядный графический метод для определения оптимального соотношения между выходом и составом целлюлозного продукта.

Задача оптимизации процесса пероксидной делигнификации древесины березы имеет следующие ограничения области поиска в факторном пространстве: $3,0 \leq \mathrm{X}_{1} \leq 6,0$; $5 \leq \mathrm{X}_{2} \leq ; 15 \leq \mathrm{X}_{3} \leq 35$ целевая функция $\mathrm{Y}_{1} \rightarrow \max$; ограничение другого выходного параметра: $\mathrm{Y}_{3} \leq 1,0$.

Задача решена средствами программы Excel. Рассчитанные значения факторов и прогнозируемых величин выходных параметров при оптимальных условиях процесса таковы:

$$
X_{1}=4,9 \% ; X_{2}=14,9 ; X_{3}=23,8 ; Y_{1}=50,2 \% ; Y_{2}=91,0 \% ; Y_{3}=1 \% ; Y_{4}=7,2 \%
$$

Химический состав и некоторые характеристики (степени полимеризации (СП), индекс кристалличности (ИК)) целлюлозного продукта, полученного в оптимальных условиях, представлены в табл. 3 .

\section{Заключение}

Установлено влияние параметров процесса пероксидной делигнификации древесины березы в среде уксусная кислота - вода в присутствии катализатора $\mathrm{TiO}_{2}$ на выход и состав цел- 
люлозных продуктов. Найдено, что наибольшее влияние на состав целлюлозных продуктов оказывает гидромодуль процесса и концентрация пероксида водорода.

В результате экспериментально-статистического анализа получены математические модели, описывающие влияние условий получения целлюлозы на ее выход и химический состав (содержание остаточного лигнина и гемицеллюлоз).

Установлена линейная зависимость между выходными параметрами: выходом целлюлозного продукта $\left(\mathrm{Y}_{1}\right)$, содержанием целлюлозы в целлюлозном продукте $\left(\mathrm{Y}_{2}\right)$, содержанием остаточного лигнина $\left(\mathrm{Y}_{3}\right)$ и содержанием остаточных гемицеллюлоз $\left(\mathrm{Y}_{4}\right)$. Получены графические зависимости между всеми выходными параметрами, которые позволяют определять оптимальные соотношения между выходом и свойствами целлюлозного продукта.

В найденных оптимальных условиях процесса пероксидной делигнификации древесины березы (концентрация $\mathrm{H}_{2} \mathrm{O}_{2}$ 4,9 мас.\%, гидромодуль 14,9, концентрация $\mathrm{CH}_{3} \mathrm{COOH}$ 23,8 мас.\%) был получен с выходом 49,9 мас.\% качественный целлюлозный продукт с низким содержанием остаточного лигнина ( $\leq 1,0$ мас.\%), высоким содержанием целлюлозы $(92,5$ мас.\%) и высоким индексом кристалличности $(0,78)$.

\section{Благодарности / Acknowledgments}

Работа выполнена в рамках государственного задания ИХХТ СО РАН (Проект 121031500180-8) с использованием оборудования Красноярского регионального центра коллективного пользования ФИЦ КНЦ СО РАН.

This work was conducted within the framework of the budget project 121031500180-8 for Institute of Chemistry and Chemical Technology SB RAS using the equipment of Krasnoyarsk Regional Research Equipment Centre of SB RAS.

\section{Список литературы / References}

1. Handbook of Finnish plywood. Finnish Forest Industries Federation, 2002, ISBN952-9506-63-5.

2. Угрюмов С.А. Исследование прочностных свойств фанеры с внутренним заполнением на основе отходов от форматной обрезки. Лесной вестник 2017. Т. 21(4), С. 42-46. [Ugryumov S. A. Investigation of the strength properties of plywood with internal filling based on waste from format cutting. Lesnoy Vestnik 2017. Vol 21(4), P. 42-46. (In Russ.)]

3. Millán G. G., Hellsten S., King A. W.T., Pokki J.P., Llorca J., Sixta H. A comparative study of water-immiscible organic solvents in theproduction of furfural from xylose and birch hydrolysate. Journal of Industrial and Engineering Chemistry 2019. Vol. 72, P. 354-363.

4. Borrega M., Larsson P.T., Ahvenainen P., Ceccherini S., Maloney T., Rautkari L., Sixta H. Birch wood pre-hydrolysis vs pulp post-hydrolysis for the production of xylan-based compounds and cellulose for viscose application. Carbohydrate Polymers 2018. Vol. 190, P. 212-221.

5. Koropachinskaya N. V., Tarabanko V.E., Chernyak M. Y., Catalytic oxidation of birch wood (Betula Pendula Roth.) with oxygen in syringaidehyde and vanillin. Khimiya Rastitel'nogo Syr'ya 2003. Vol. 2, P. 9-14.

6. Sixta H. Handbook of pulp. Wiley-VCH Verlag GmbH \& Co, Weinheim. 2006.

7. Jiménez L., Pérez A., Rodríguez A., de la Torre M. J. New raw materials and pulping processes for production of pulp and paper. Afinidad 2006. Vol. 63(525), P. 362-369. 
8. Rodríguez A., Jiménez L. Pulping with organic solvents other than alcohols. Afinidad 2008. Vol. 65(535), P. 188-196.

9. Villaverde J. J., Ligero P., Vega A. Fractionation of Miscanthus x Giganteus via modification of the Formacell process. Industrial Crops and Products 2015. Vol. 77, P. 275-281.

10. Ligero J., Vega A., Villaverde J.J. Delignification of Miscanthus $\times$ Giganteus by the Milox process. Bioresource Technology 2010. Vol. 101, P. 3188-3193.

11. Villaverde J.J., Li J., Ligero P., Ek M., Vega A. Mild peroxyformic acid fractionation of Miscanthus $\times$ giganteus bark. Behaviour and structural characterization of lignin. Industrial Crops and Products 2012. Vol. 35(1), P. 261-268.

12. Song Y., Wi S.G., Kim H.M., Bae H.J. Cellulosic bioethanol production from Jarusalem artichoke (Helianthus tuberosus L.) using hydrogen peroxide-acetic acid (HPAC) pretreatment. Bioresource Technology 2016. Vol. 214, P. 30-36.

13. Кузнецов Б. Н., Кузнецова С. А., Яценкова О. В., Данилов В. Г. Получение целлюлозы каталитической делигнификацией древесины пероксидом водорода. Монография. Красноярск: CФУ, 2014. 146 c. [Kuznetsov B.N., Kuznetsova S. A., Yatsenkova O. V., Danilov V.G. Receiving cellulose by catalytic delignification of wood with hydrogen peroxide. Monograph. Krasnoyarsk: Siberian Federal University, 2014. 146 p. (In Russ.)]

14. Ferrer A., Vega A., Rodriguez A., Ligero P., Jimenez L. Milox fractionation of empty fruit bunches from Elaeis guineensis. Bioresource Technology 2011. Vol. 102, P. 9755-9762.

15. Kuznetsov B. N., Sudakova I. G., Garyntseva N. V., Djakovitch L., Pinel C. Kinetic study of aspen-wood sawdust delignification by $\mathrm{H}_{2} \mathrm{O}_{2}$ with sulfuric acid catalyst under the mild conditions. Reaction Kinetic Mechanisms and Catalysis 2013. Vol. 110, P. 271-280.

16. Kuznetsov B.N., Levdansky V.A., Kuznetsova S.A., Garyntseva N.V., Sudakova I.G., Levdansky A. V. Integration of peroxide delignification and sulfamic acid sulfation methods for obtaining cellulose sulfates from aspen wood. European Journal of Wood and Wood Products 2018. Vol. 76, P. 999-1007.

17. Пен Р.3. Планирование эксперимента в Statgraphics Chenturion. Красноярск, 2014. 292 с. [Pen R.Z. Planning an experiment in Statgraphics Chenturion. Krasnoyarsk, 2014. 292 p. (In Russ.)] 